\title{
História e literatura
}




\title{
"História é um esboço":
}

\section{a nova autenticidade narrativa na historiografia e no romance}

\author{
EBERHARD LÄMMERT
}

A RELAÇÃO ENTRE historiografia e romance pode ser descrita desde pelo menos duzentos anos como uma alternância de aproximação e repulsão. Séculos atrás o romance, como "poema da História", estava assinalado com a mácula da fabulosa res fictae e permanecia assim à sombra da História. Somente as ondas expansivas da Querelle des Anciens et des Modernes elevaram o romance, como órgão da era moderna, à categoria que na antigüidade se atribuía às epopéias homéricas. Nesse novo papel, o escritor de romances pôde ser então logo classificado como "criador e historiador ao mesmo tempo" (1), como na saudação incentivadora que Friedrich von Blanckenburg dirigiu em 1774 aos futuros autores de romances nacionais.

Pouco depois os romances de Walter Scott haviam-se transformado em meia Europa na mais cobiçada leitura de história, e muitos de seus contemporâneos escoceses formaram efetivamente sua visão do próprio passado a partir desses romances históricos. Por seu turno, os historiadores - não por último em virtude do desenrolar dramático da Revoluçáo Francesa - ganharam novo alento para a concepção de grandes narrativas históricas. Em suas cartas sobre a História da França, Augustin Thierry declarou sua preferência explícita pela representação épica dos movimentos históricos. O capítulo sobre o levante do Terceiro Estado - ele o sabia de antemão - "me sairá melhor se eu substituir o tratado cientifico pela narrativa, se eu próprio colocar-me em segundo plano e deixar os fatos falarem” (2). De Roland Barthes há uma análise tão obstinada como rigorosa sobre a arte compositiva - esta mesma quase que umLeitmotiv - com que Jules Michelet trouxe suas "obras monumentais sobre a história da França para a vizinhança da epopéia homérica” (3). Na Inglaterra, Macaulay tornou-se o grande narrador de uma História da Inglaterra que se valeu da arte scottiana de, ao lado dos protagonistas da história política, convocar toda uma imensidão de histórias do povo que, como ele próprio diz, "fazem o encanto dos romances históricos" (4). Também Ranke compôs, como vemos hoje, à base de Leitmotive, conforme as idéias de peso histórico acentuadas por ele, e coloria as cenas decisivas quando se propunha a narrar "como realmente foi" (5). 
Ao contrário, Johann Gustav Droysen - o primeiro sistematizador decidido de uma historiografia profissional - fez da investigação histórico-científica das fontes uma condição preliminar de toda autenticidade, e no mesmo ato em que alçou seu modelo Ranke à condição de "maior historiador do nosso tempo" censurou-lhe com certa indulgência o fato de "muitas vezes estar ainda em suas exposições muito próximo do romance de Walter Scott" (6). Enquanto entre os historiadores alemães o manuseio de uma crítica erudita das fontes recebeu o valor de uma distinção e também na exposição ia reivindicando um espaço sempre maior, um jovem historiador, Viktor von Scheffel, levantou novo protesto com um estudo sobre a Idade Média que, concebido como tese de livre-docência, transformou-se inesperadamente em um romance. No prefácio à história de um herói romanesco inspirado nas figuras de quatro abades, o autor declara ser o romance histórico não apenas "irmão igual da História", mas também uma complementação necessária daquela "literatura de eruditos para eruditos, pela qual a maioria da nação passa sem tomar parte." Somente o romance extrairia de notícias legadas $o$ retrato completo de uma época passada, e transformaria esta para o leitor em uma vivência imediata, ainda que nisso "pessoas e datas ... não raro se confundam um pouco" (7). E, mais uma vez, Conrad Ferdinand Meyer acredita dois decênios mais tarde ter erigido ao seu contemporâneo Bismarck, na poderosa e sombria caracterização do seu "Jürg Jenatsch", um retrato mais fiel do que o poderia fazer uma minuciosa biografia de Bismarck (8).

Por essa época, todavia, os próprios historiadores europeus já discutiam acaloradamente como a dependência de todo destino individual em relaçáo a determinantes econômicos ou também biológicos, aos quais as emergentes ciências naturais haviam conferido força de lei, seria compatível ainda com uma exposição narrativa progressiva. A complexidade das instituiçóes, cuja análise Fustel de Coulanges foi o primeiro a empreender (9), da mesma forma a difusão de motivos sociais, apresentados então pela ascendente historiografia materialista, exigiram um esforço de análise e descrição sistemática que foi se tornando cada vez mais incompatível com um relato fluente da marcha das coisas. Nessa mesma época - e não independentemente desse desenvolvimento - descrições e diálogos caracterizadores do meio social impediam a fluência da narrativa no romance social europeu, em Zola tanto quanto em Reade ou Kielland; e no limiar do novo século a crise de uma narrativa fidedigna estava exposta juntamente com a crise do historismo.

\section{Colombo e seu feito}

Ao invés de uma análise de fatores, que teria de recuar muito, vamos examinar as dimensóes dessa crise através de duas questóes simples. A primeira questão diz: "Como se deu que Colombo descobriu a América no ano de 1492?" A segunda, ao contrário, diz o seguinte: "Como se deu que a América foi descoberta 
por volta de 1500 a partir da Europa?” (10) Fica evidente que para se responder a uma e outra questão são necessários não apenas conhecimentos diferenciados, mas também estilos diferentes. A questão de como Colombo conseguiu tal coisa deve ser respondida com uma narrativa que tenha sua pessoa em posição central, e pode-se imaginá-la amplamente enfeitada com acontecimentos dramáticos, episódios folclóricos e características vívidas. Sem dúvida ela se presta a um romance; mas aịnda até a metade do século XX não faltaram historiadores que narraram Colombo e seu feito - assim diz um título de Richard Hennig (11) - como história de eventos.

A outra questão coloca a necessidade, ainda antes de se começar a desenvolvêla, de toda uma série de trabalhos preliminares. As investigações devem estenderse ao comércio contemporâneo com as Índias, aos interesses díspares das coroas portuguesa e espanhola, à astrologia contemporânea, à construção naval e à arte navegatória; as investigaçóes devem ocupar-se também das constelações familiares e políticas que levaram ao envio sucessivo de uma frota das Índias Ocidentais. Faz-se necessário aqui trabalho analítico, e seu resultado dificilmente poderá ser a apresentação de uma cadeia linear de eventos, e de forma alguma Colombo estará em posição central como pessoa que tudo decide. Seguindo esta concepção, um romance inchar-se-á numa profusão de ações paralelas e, assim, entrará facilmente em algo imprevisível.

O historiador holandês Johan Huizinga foi o primeiro que, num ensaio "sobre uma mutação formal da História a partir da metade do século XIX" (12), apontou como responsável pelo deslocamento inédito da primeira para a segunda questão uma transformação na natureza dos próprios acontecimentos históricos. Tomando como exemplo o movimento americano pela Independência e a história dos Estados Unidos no século XIX, Huizinga discute como questóes financeiras - livre-comércio, financiamentos bancários, operaçôes cambiais, investimentos em transportes e abertura de estradas - vão cada vez mais assumindo feição política e, com isso, tornando-se determinantes para as formas de vida e para a distribuição de poder no continente cuja conquista e povoamento estavam em um grau mais avançado. Uma vez mais, a guerra entre os estados do norte e do sul traz uma fase de acontecimentos épicos e plásticos, e Huizinga não hesita em afirmar que essa "épica" está "nos próprios fatos. Abraham Lincoln e Robert Lee defrontam-se como os vultos de um Agamenon e de um Heitor" (13).

Isto coincide com as teses levantadas há apenas dez anos pelo historiador inglês Lawrence Stone, o qual constatou que todos os fatos de base pessoal e todos os fatos casuais, portanto tudo aquilo que se deve atribuir às categorias maquiavélicas de virtù e fortuna - todo elemento individual não sujeito a regras não pode ser representado de outro modo senão narrativamente (14). Huizinga já formula a inversão desse argumento: recuando "o elemento pessoal da História 
em prol do coletivo", então "as séries de eventos não compóem mais nenhuma forma, as relaçôes são privadas de linha e as situaçóes praticamente não se deixam mais representar de maneira plástica" (15). Tais eventos coletivos constituem, porém, em grau crescente, as forças propulsoras do processo histórico - se é que as forças econômicas dominam os fatores ideais e propriamente políticos do desenrolar histórico.

Vê-se que, para Huizinga, critério para as crescentes dificuldades para tornar a História presente ațravés da narrativa não é uma mudança nos recursos expositivos, mas sim uma mudança na determinação do processo histórico. Mas Huizinga logo tem exceçóes à mão: a seu ver, com o surgimento de Theodore Roosevelt as correlações se alteraram de imediato: com seus discursos e suas intervenções enérgicas na história econômica da América, Roosevelt logo ofereceu, como "vulto marcante", uma figura narrativa na qual se podem caracterizar os traços essenciais da época.

Podemos ver hoje que também as ciências da ação e do comportamento que na virada do século se consolidam sobre novas bases - psicologia, sociologia, economia política e etnologia - ensejam cada vez mais abordar processos históricos de diferentes lados e, nisso, inferir as forças condutoras a partir de seus respectivos conhecimentos específicos. Assim, mesmo pessoas que no século XX arrebatam para si um imenso poder serão interpretadas futuramente, por uma historiografia crítica, antes a partir dos dados do seu meio contemporâneo do que dos seus traços de caráter - a não ser que o caso seja, como em algumas biografias de Hitler, de interesse patológico.

Todavia, historiografia e romance reagiram a essa situação de maneira extremamente diversa. É verdade que tanto romancistas como historiadores aceitaram o desafio de se aventurarem numa representação de movimentos históricos anônimos e coletivos. Os autores de romance reagiram com uma ampla dissolução do fluxo narrativo em prol de uma mudança forçada de estilo e perspectiva, mas também com uma multiplicação do espectro entre experiência passada e presente: discurso indireto livre e monólogo interior tornam-se os instrumentos de tal imbricação de diferentes níveis de experiência. Os historiadores, ao contrário, reagiram com uma especialização dilatada de suas exposiçóes. Pois apenas o decidido estreitamento do seu campo de pesquisa permitiu aquilo que a rigorosa exigência de verdade, reformulada pelas ciências naturais, reivindicava: a dedução segura dos motivos na produção de uma cadeia causal de provas. Do tratamento isolado de forças econômicas ou socialmente determinadas - propulsionadoras da transformação de situações históricas -, ou da consideração de princípios darwinistas de seleção natural, ou ainda a partir de teorias materialistas de classes sociais puderam ser tecidos outros "fios condutores" para se converterem conflitos reconhecidos ou transformaçôes em história. No bojo de tal especialização foi 
sobretudo a história econômica que se tornou um campo próprio da representação historiográfica.

A essa especialização contrapõem-se tentativas de novas sínteses. Em Cambridge por exemplo, na virada do século, elas já levam ao projeto monumental de elaborar uma Cambridge Modern History, em doze volumes, com a participação de inúmeros historiadores. Na França Henri Berr criou uma série em cem volumes de monografias históricas que deveriam ser escritas por respectivos especialistas, e chamou essa série, em alusão à Comédie Humaine de Balzac, de L'Évolution de l'Humanité (16). Interessante nessas concepções sintetizantes é, em especial, que os autores isolados estavam convocados a renunciar meticulosamente à singularidade da perspectiva própria para garantir uma visão uniforme do todo. "Pois", assim escreve Lord Acton em uma carta aos colaboradores da Cambridge Modern History, "a participação de opiniōes pessoais levaria a uma confusão tal que toda unidade do plano soçobraria" (17). De resto, vê-se como ao contrário da ciência alemã da História, que fundamentou sua "objetividade" com a virtude de uma crítica especializada das fontes - a "objetividade" nesse empreendimento anglo-saxônico é entendida preponderantemente como uma virtude social, a qual se exprime em última instância, para Lord Acton, no fato de que ninguém possa dizer depois onde um cardeal francês descansa a pena e um positivista inglês ou um historiador alemão do direito a toma.

\section{História anônima e "vultos marcantes"}

Em uma breve amostra textual já se podem assinalar transformaçôes lingüísticas características que, no decorrer do século XX, resultam de uma tal entrega da historiografia a especialistas mesmo quando o fluxo narrativo é mantido. Escolho para isso a concepção de uma história social e econômica dos séculos XIX e XX que Helmut Böhme esboçou energicamente em 1968, em oposição a uma historiografia presa de forma convencional a pessoas. Será interessante aqui dirigir a atenção aos sujeitos do trecho que vem a seguir.

"119 sociedades acionárias foram fundadas na Prússia entre 1851 e 1857 ... Se em 1850 o continente ainda não sofria de escassez de dinheiro, isto se modificou rapidamente nos anos seguintes. Na esteira da liberalização da mineração do ferro e do carvão surgiu no vale do Ruhr um sem-número de empresas com, para padrões alemães, considerável recurso de capitais...”

Por esses motivos foi-se obrigado de antemão na Alemanha - em especial na Prússia - a procurar novos caminhos de obtenção de capital para - sem a retaguarda de uma acumulação de capital no comércio exterior, de um adensamento progressivo da atividade industrial e manufatureira, como na Inglaterra - organizar o emprego concentrado dos capitais. Os recursos das classes possuidoras ha- 
viam-se revelado demasiado parcos, e a agricultura mostrara pouca inclinação para participar da industrialização e da recanalização das reservas de capital. A tentativa dos empresários de ainda financiar o crescimento industrial com créditos e capital próprios teve de fracassar em face das rápidas taxas de crescimento... Assim foi-se às ruas já nos anos cinqüenta, pois tratava-se de abarcar também os recursos financeiros médios e pequenos, de os juntar e aplicar lucrativamente no processo industrial. A ação entrou em moda" (18).

Vale a pena alinhar os sujeitos destas frases, um atrás do outro, para ver quem faz história aqui: "119 sociedades acionárias - o continente - um semnúmero de empresas - os recursos das classes possuidoras - a agricultura, etc.” Mencionam-se exclusivamente sociedades, instituições, regióes territoriais e abstratos como "sem-número" ou designaçóes de processos como "tentativa". Nas últimas frases vem juntar-se ainda um sujeito característico, isto é, a pequena e impessoal palavrinha "se": "Por esses motivos foi-se obrigado ..." e: "Assim foi-se às ruas já nos anos cinqüenta, pois tratava-se de ..." Também este último "se" é típico desse estilo narrativo. A gente chega a ficar feliz quando volta a aparecer um verdadeiro sujeito: "A ação entrou em moda."

Trata-se aqui, bem entendido, de uma exposição que apresenta o seu objeto numa seqüência concentrada de levantamentos isolados e resultados analíticos. Também em um tal estilo que não mais conhece pessoas individuais como portadoras de decisões, sucedâneos de mitos estão mais presentes do que se presume -: se "a burguesia" ou "o capital", enquanto sujeitos, são formalmente estilizados em figuras atuantes e porventura até mesmo dotadas de capacidade de raciocínio e de vontade.

Por um momento vamos contrapor a uma tal exposição uma frase como aquela com que Leopold Ranke, há quase um século e meio, se lança às suas histórias dos povos românicos e germânicos. Ranke começa assim: "No início de sua felicidade, não muito tempo após o início da migração dos povos, o rei visigodo Ataulfo pensava em fazer da Romênia uma Gódia e de si um César" (19). O abismo parece intransponível e, contudo, coloca-se a questão de como uma historiografia do século $\mathrm{XX}$, com exigências científicas e que se orienta por determinantes suprapessoais, deve descrever por seu turno o papel de um soberano, de um político significativo ou de um líder militar.

A historiografia marxista é menos embaraçada, descontando-se os testemunhos devotos do culto à personalidade, para inserir destacadas figuras históricas na marcha dos acontecimentos: ela as desenha como impulsionadoras de processos cuja necessidade é determinada pela formação social da qual elas provêm (20). E que processos revolucionários - para assegurar a tais figuras, no contexto de predeterminação, um grau mínimo de tensão expositiva - sejam os primeiros 
a atrair a atenção para si, este fato não tem apenas razões prescritas, mas também razões que em certo sentido já vêm inscritas; pois apenas aqui as correntes de ação e reação, encarnadas na figura de protagonistas típicos da época, são as primeiras a agir de forma individual - corajosa, desesperada ou violentamente - $\mathrm{e}$ assim, no âmbito do processo geral delimitado pela teoria da História, abrem espaço também a situações surpreendentes e até mesmo às categorias pessoais de virtì e fortuna. Mas permanece aqui, com força decisiva, a exigência de que a exposição, em toda a singularidade dos conflitos concretos, deixe transparecer a totalidade do processo global.

Teoria do romance e teoria da História modernas encontram-se aqui num ponto crucial. Pois já o romance de formação clássica não deveria ser apenas um "quadro de costumes", mas também "um espelho da marcha geral das coisas humanas e da vida" (Schelling) (21); e também Balzac situa muitos de seus romances sobre a época contemporânea em pontos de intersecção do conflito entre o poder corroído da nobreza e o poder emergente do dinheiro, e faz com que suas figuras desenvolvam paixões que são apenas a expressão híbrida de coerções sociais. Georg Lukács, que já na sua clássica Teoria do romance relaciona o desdobramento do gênero com limiares de época, desenvolve mais tarde, como exigência feita ao romance socialista, um tipo de herói que mesmo enquanto figura do cotidiano deve representar a individuação de uma força política que ajuda a executar a ruptura necessária de uma formação social. Em sua controvérsia com Adorno, ele fundamentou minuciosamente como a capacidade de narrar história pressupóe uma certeza sobre o lugar e o significado da ação no processo histórico geral (22). Todavia, Lukács faz valer implicitamente um pressuposto tradicional que o narrador de séculos passados podia estabelecer genericamente pelo simples motivo de que o seu público lhe concedia uma dianteira no conhecimento de causa: quem tem a confiança do público neste ponto não deve descrever a ação das personagens de fora e em busca de explicaçóes; ele pode narrá-la, no contexto de uma seleção concedida dos elementos significativos, de maneira fidedigna.

Também o biografismo histórico, que a partir da metade do século recomeça hesitante na Europa ocidental, esforçou-se - é verdade que sem preceitos de semelhante rigidez - em determinar em novas bases a relação entre a vontade própria de uma figura histórica e o seu papel como mera expressão das relaçóes sociais. O historiador muniquense da Antiguiidade Christian Meier examinou essa questão em um estudo com o caprichoso título: "Da dificuldade de narrar uma vida. A respeito do projeto de uma biografia de César" (23). Para Meier, já a necessidade de fornecer fundamentos a cada frase caracterizadora da personalidade proíbe que se proceda de maneira continuamente narrativa. Pois também aqui faz-se necessário alicerçar o narrado nos dados do sistema econômico e político em que a vida de César se desenvolve. Meier, porém, lança mão do recurso - à semelhança de Huizinga - de responsabilizar a situação político-social em que 
César se alçou a ditador pela circunstância de que a partir de então a história pode ser narrada da perspectiva da ação soberana de uma figura. Na república tardia de Roma Meier desvenda uma situação de crise na qual as diversas forças no interior do sistema haviam caído em tamanha desproporção entre si que todas elas, mesmo não o querendo incondicionalmente, mantêm em funcionamento o processo imprevisível de crise. O poder parcial dos aristocratas e o senado com seus senadores haviam-se paralisado de forma tal que nenhuma das instituições estava suficientemente poderosa para estabelecer a ordem por si própria, e isto permitiu a César solidarizar o descontentamento de amplas camadas a ponto de estas esperarem apenas dele a supressão do estado de desordem.

César aparece na exposição de Meier, muito semelhante ao Jürg Jenatsch de Conrad Ferdinand Meyer, como um líder de formato quase sobre-humano, não ligado a qualquer contrato e seguindo fortes impulsos pessoais. Declarando seus interesses próprios, ele pode até mesmo desencadear uma guerra civil e por tal ato de vontade logo ser honorificado "quase como um deus". Christian Meier faz bem em expor abertamente em sua concepção experiências do século XX.

Tomando agora o princípio clássico, reanimado já por Schiller e depois ainda por Lukács, segundo o qual a arte individualiza leis gerais da vida em figuras e processos concretos, então uma exposição biográfica deve, pelo caminho inverso, permitir que se coloque a questão de sua representatividade para relações mais gerais. Por isso é preciso demonstrar justamente numa exposição biográfica como autores reagem de forma diversa para dar conta da obrigação inapelável de fornecer fundamentos para os feitos incomuns do indivíduo particular. Com máxima brevidade estabeleço aqui uma contraposição entre um historiador, um biógrafo que escreve romanescamente e um romancista. Cada um deles escreveu um livro com o mesmo título Wallenstein, e vou escolher a cada vez o mesmo episódio pequeno e espinhoso do qual depende o julgamento total de Wallenstein: ele quis agir taticamente ou cometeu traição quando permitiu, em novembro de 1631, que o marechal saxônico von Arnim entrasse sem luta em Praga?

\section{Wallenstein: estrategista ou traidor?}

O historiador tcheco-eslovaco Josef Pekar, nos dois volumes de sua obra de vida Wallenstein 1630-1634. Tragédia de uma conspiração (24), trata aquilo que as fontes oferecem como fatos com todo o cuidado. Frases como esta: "Deve ter sido ele próprio que encorajou Arnim a marchar em direção de Praga" (25) são típicas do traço fundamental da sua forma de expor: não narrar ele próprio, mas sim deixar que as fontes relatem. Uma grande parte do livro sequer se dedica aos acontecimentos $\mathrm{cm}$ si; ela questiona, antes, se - e em que medida - as testemunhas da época, das quais relatam as fontes - e com isso as próprias fontes -, são por sua vez dignas de crédito. Naturalmente Pekar não esquece em nenhuma 
etapa de sua análise de elucidar pesquisas mais recentes sobre o mesmo objeto e, via de regra, estabelecer distância crítica. Um típico trabalho de erudição.

A exposição analítica, que Droysen já havia diferenciado da narrativa e comparado com um processo criminal (26), ocupa em Pekar o mais amplo espaço. Os processos presumíveis ou por fim provados, sobretudo os motivos constatados da ação de Wallenstein, são antes expostos de forma tética do que propriamente narrados. Levantamento de provas e justificativa do próprio procedimento ocupam em larga escala o lugar da narrativa: traços de uma conduta de corporação científica - não restrita a historiadores, mas que necessariamente diferencia cada vez mais também o estilo de uma historiografia especializada do estilo narrativo. Aliás, uma comparação entre os escritos do jovem e do tardio Ranke permite que se reconheça com clareza como essa mutação se prefigura já no século XIX, com a transformação da historiografia em ciência, o que, por sua vez, confere ao protesto de Viktor von Scheffel um tom não apenas polêmico mas também profético.

Também para Pekar, mais importante do que Wallenstein torna-se a justificação do próprio juízo sobre ele. Mas este Pekar já fixou, ou antes ou depois, no subtítulo: Wallenstein foi um conspirador.

Golo Mann (27) começa igualmente com uma explanação sobre as fontes cita uma carta de Wallenstein a von Arnim com a frase: "Pois ao cabo, quando a maioria dos países estiver em cinzas, ter-se-á de fazer a paz, como esses exemplos da guerra que se estende pelo décimo-quarto ano nos têm demonstrado". E então Golo Mann prossegue lapidarmente: "Essa era sua disposição e sua vontade... Ele já tinha lucrado bastante com a guerra, estava cansado agora, mais do que nunca atormentado pela gota; ... Era preciso vir a paz para que ele tivesse paz" (28). Golo Mann não ausculta as fontes para estabelecer sua autenticidade ou seu caráter tático; ele simplesmente utiliza aquelas que pode usar e extrai daí, de maneira direta e calorosa, argumentos para sua concepção da figura de Wallenstein. Ele deve aparecer aqui como o príncipe da paz, um sábio que após todas as atribulações suportadas só pensa agora na tranquiilidade do mundo - e para que o biógrafo possa armar cenicamente este seu intuito, Arnim tem, num diálogo posterior, de assumir o papel do tático antes pálido, algo pedante: um modelo literário Fausto/ Wagner. Golo Mann trabalha aqui, portanto, com meios dramáticos para moldar a imagem de caráter desejada. No mais, a literatura crítica, à medida que contraria suas constelações, é despachada asperamente como uma "leitura maluca" ou "palavreado de terceira ou quarta mão" (29). Golo Mann, de fato, não é mais historiador, ele apenas foi um - um Viktor von Scheffel do nosso século.

Para adornar as cenas que, na sua intenção, revelam o caráter de Wallenstein, Alfred Döblin (30) trabalha em seu romance Wallenstein com os fatos históricos 
conhecidos de forma ainda mais inescrupulosa do que Golo Mann. Wallenstein aparece aqui como alguém que usa seu antigo subordinado von Arnim como um instrumento para se vingar do imperador Ferdinand pela ignomínia que sofrera durante a dieta de Regensburg. Para moldar esse Wallenstein, Döblin confere inversamente ao imperador Ferdinand os traços de um asceta que se purifica em um novo homem, frente ao qual Wallenstein aparece como um grande manipulador que age tática e ocultamente, que trata seus amigos como inimigos e inimigos como amigos, explorando a todos para seus fins: em Döblin, um típico homem de concepções obsoletas.

Mas narrativamente isto é apenas um lado da caracterização que Döblin faz de Wallenstein. Em um furioso espetáculo cênico Döblin exibe aquilo que acontece com Wallenstein à sua revelia. A tomada de Praga pelos saxões desemboca nesse cenário em um ato de libertação coletiva. Cada frase, mesmo cada segmento de oração, fala de novos homens, os quais despontam no tumulto e são empurrados para diante, até mesmo os crânios de antigos rebeldes, espetados até então na ponte sobre o rio Moldávia para fins de intimidação, tornam-se agora participantes. Mas também nesse acontecimento coletivo o narrador mantém a atenção voltada para todos os lados: as gigantescas procissóes que, brotando de todas as partes da cidade, vão rolando espontaneamente em direção da Catedral de São Vito avultam em nova ameaça para os saxóes, de tal forma que os conquistadores acabam por ficar contentes "quando o povo desenfreado desencadeia os primeiros ataques à cidade dos judeus" (31). Döblin não narra senão detalhes, mas o que importa é o ondulante quadro geral que surge daí, no qual indivíduos ficam, no processo de transiçăo, visíveis por alguns segundos, enquanto um grande número de pessoas que disseminam a violência e um número ainda maior de pessoas que a sofrem dominam a cena.

Com esse procedimento narrativo Döblin logra, já em 1920, fazer com que movimentos coletivos se tornem narráveis a partir de uma história de vida. A pessoa de Wallenstein aparece aqui, em última instância, tão-somente como o catalisador de um tal movimento histórico. Todavia, esses movimentos precisam, a curto prazo, tornar-se sensorialmente visíveis; e, por isso, é sobretudo em tais cenas de grande movimentação que autores como Tolstoi, Zola, Henrich Mann e mesmo Döblin desenvolvem a arte de narrar histórias de movimentos de massa e conflitos entre coletivos. A diferença saliente em relação a uma exposição de conflitos sociais determinados consiste no fato de que essa forma de representação, imagética e valendo-se de perspectivas múltiplas, deixa ao acontecimento coletivo a aparência de um movimento espontâneo e autônomo. Em seu considerável estudo sobre "Wallenstein", História como fiçẫo (1986), Axel Hecker investigou como a exclusão prática de toda explicação causal é determinante para a impressão de uma tal espontaneidade (32). O que o indivíduo particular significa, isto não é narrado, mas sim que tudo se dá concomitante e inexoravelmente. 
Este é o ponto do qual advém a arte narrativa da segunda metade do século $\mathrm{XX}$, a qual oferece não mais significado, mas, quando muito, possibilidades de combinaşão.

O romance nacional-socialista e, do mesmo modo, a historiografia nacional-socialista procederam nesse ponto de maneira exatamente inversa: eles estilizaram coletivos retoricamente em indivíduos superiores e os equiparam com traços de caráter inequívocos e também com capacidade de ação. Em conseqüência, puderam ser atribuídas a representantes isolados de tais coletivos qualidades suprapessoais que, inevitavelmente, constituíam também o seu ser pessoal. Com esta técnica eles não apenas incorporaram traços de inimigo a pessoas isoladas também imputaram à História coletivos imaginários como "os arianos" ou "os membros do povo" como indivíduos pretensamente superiores. Ainda hoje, quando se fala da história dos anos 30, a contraposição apressada de "alemães" e "judeus" nada mais é do que a repetição irrefletida de diferenciaçóes que os nacional-socialistas criaram quando começaram, em 1933, com a divisão dos alemães. Aliás, investigando em romances escritos em língua alemã por volta de 1930 esses sintomas - a transferência de traços essenciais de coletivos imaginários para figuras particulares de seu enredo - poder-se-ia precisar em cima deste único ponto quais dos escritores aqui reunidos puderam continuar escrevendo na Alemanha depois de 1933 e quais não puderam.

\section{A História em romances do pós-guerra}

O enfrentamento narrativo de processos coletivos em romances sobre a época mais recente tornou-se uma necessidade histórica quando os autores da primeira geração do pós-guerra se propuseram em suas histórias a trabalhar o envolvimento de milhões de pessoas nos crimes nazistas - e não se comportando como um Pilatos. Autores como Günter Grass nò seu Tambor de lata ou Claude Simon em La Route des Flandres solucionaram esse problema narrativo ao dar às suas histórias um horizonte autobiográfico. A necessidade de narrar experiências e situaçóes de vida simultâneas e, contudo, duramente antagônicas fez com que essa geraçáo de escritores buscasse primeiro a adesão à perspectiva múltipla da arte narrativa dos anos 20. Claude Simon, por exemplo, liberta-se das imposiçóes de um nexo causal através de "uma meditação em livre associação - que se move em múltiplos círculos e voltas - de um Eu que vai se recordando", e permite assim que "os fragmentos heterogêneos da realidade" ganhem um contexto puramente subjetivo, mas por isso mesmo o único porventura ainda fidedigno (33). Günter Grass confere um contraponto às viragens exaltadas da história à medida que impede o seu indestrutível herói Oskar Matzerath de desenvolver-se no meio social odiado. Nos Anos de cão os narradores se revezam e libertam assim o todo histórico da hegemonia de um juízo pessoalmente marcado ou mesmo de um preconceito. 
Ainda com mais requintes de minúcia, Uwe Johnson manuseia em seus romances a alternância de perspectivas para enfocar a história quase impenetrável do período nacional-socialista e da Alemanha do pós-guerra. Suas Suposicôes sobre Jakob e as tentativas sempre frustradas do narrador no Terceiro livro sobre Achim comportam-se antes como investigaçóes no sentido de Droysen. Na obra de vida de Johnson, o romance em quatro volumes Dias do ano, vários níveis de tempo e camadas de memória de diferentes figuras imbricam-se por fim a tal ponto que essa interpenetração mútua aparece como uma forma moderna de experiência da realidade. Assim, as pessoas particulares transformam-se em prismas nos quais experiências históricas se enfeixam e são refletidas sobre outras. Mas também aqui cada pessoa mantém ainda o seu valor testemunhal, vira por assim dizer uma fonte que é testada em sua capacidade de prestar depoimentos. Na última página do seu romance em quatro volumes, o autor dá ainda um passo para além desse arranjo. Ele faz com que o velho professor de sua figura principal, Gesine Cresspahl, recorde uma frase do obstinado pai da aluna, o qual diz com simplicidade de todos os empenhos no sentido de invocar uma imagem do passado fiel à verdade: "História é um esboço" (34). Todos os esforços - tanto os de um minucioso crítico das fontes quanto os de um romancista que esboça sinteticamente suas concepçốes - e, de resto, todas as imagens que cada um faz para si do passado são atingidos por essa única frase. Ela contém a indicação de que a história vem a nascer tão-somente nesses esboços que sob a forma de histórias lembradas ou anotadas entregam o passado ao presente.

Enquanto para o romance isso é relativamente fácil de se perceber, foram necessários esforços consideráveis para que a realidade e o caráter de tais esboços adquirissem validade também para o procedimento de toda e qualquer historiografia. Foi Hayden White quem abriu caminho energicamente para uma análise dessa condição fundamental comum ao narrar científico e ficcional da História (35). Na França, entretanto, a École des Annales já tinha, através dos trabalhos de Marc Bloch e Lucien Fèbvre, preparado uma historiografia que, com a preferência por dados e construçóes sociológicos, distanciou-se necessariamente de toda historiografia romanesca. Pois todo historiador que dirige sua atenção menos aos acontecimentos políticos de superfície do que às relações sociais que os fundamentam, "elege ... de preferência fatos comparáveis e recorrentes" (36) e subordina assim a dimensão temporal a uma lógica associativa que vai conduzindo de fato a fato. Ele apresenta como princípio ordenador tanto de uma história de hábitos alimentares como de uma histoire totale "estruturas", e se aí surgem ainda atores isolados, então são aqueles que representam interinamente o comportamento coletivo. A estratificação de épocas históricas, que Braudel passou à geração seguinte de historiadores (37), também contribuiu para representar a história de tempos mais remotos como complexo de formaçôes, e somente a historiografia literária permanceu, como Roland Barthes pôde troçar ainda nos anos 60, mais ou menos no nível metódico das velhas crônicas reais (38). 
$\mathrm{Na}$ Alemanha dos anos 60 , ao contrário, foram os romances sobre a história recente que - com seus experimentos formais em parte forçados e em parte lúcidos, também com a questão pungente de como extrair um sentido de atos pessoais ou mesmo dos sofrimentos da geração dos pais - desenvolvem novos métodos da representação histórica, enquanto entre os historiadores a reflexão, há muito necessária, sobre os princípios condutores de sua historiografia só começa no decorrer dos anos 70. Com as duas primeiras versões de sua Descrição de batalba (39) em 1964 e 1968, Alexander Kluge preludiou uma forma de apresentação que remete exteriormente à configuração de histórias especiais, mas que tem como meta declarada o esboço de um modelo geral das relações sociais. $\mathrm{O}$ livro de Kluge sobre Stalingrado apreende a derrocada do sexto exército alemão numa rede de documentos, prescrições, reportagens e entrevistas, demonstrando assim o envolvimento de todas as pessoas em um "mundo de formas" (40), no qual elas falam e agem, conforme as instruçóes, até a morte ou o cativeiro. Também aqui, portanto, como já ẹm Huizinga e mais tarde em Christian Meier, não se experimenta arbitrariamente com uma nova forma, mas se pressupõe que $o$ próprio processo histórico assumiu essa estrutura: uma estrutura, a saber, na qual as pessoas que aparentemente agem, do general até o último enfermeiro ou mesmo o sacerdote militar, adaptaram o comportamento, seguindo uma tradição de longas geraçốes, ao esquema social determinado pelo mando e pela submissão, de forma que, em conseqüência do seu treino de obediência, seguiram por fim as ordens não tradicionais de Hitler como lemingues suicidas.

Com essa combinação de relatórios da Webrmacht, prescrições militares e entrevistas, Kluge passa ao leitor muita responsabilidade para uma recepção fecunda. Contudo, a história que o leitor deve compor para si próprio constitui-se em partes bastante consideráveis em discursos e material escrito. Mas com isso Kluge apenas reproduz a maneira pela qual as histórias se desenvolvem a partir de fatos que não falam, e assim ele delineia a grande participação que os discursos já existentes têm na nossa experiência de fatos passados.

Essa demonstração do surgimento de história coletiva a partir de notícias soltas, relatos de testemunhas, documentos e lendas, Hans Magnus Enzensberger a desdobra em seu romance $O$ curto verão da anarquia. Nos documentos e relatos combinados por Enzensberger são os próprios envolvidos que têm a palavra, e eles todos jamais falam dos acontecimentos vivenciados sem expor junto a própria situação, os seus sofrimentos e esperanças. Contudo, o próprio autor aparece não apenas como um simples montador, mas ao mesmo tempo também como o porta-voz de todos e, assim, como aquele que carrega a principal responsabilidade pela consciência histórica coletiva que vai se formando (41).

Já o espaço de tempo notoriamente curto abarcado pelas obras Os dias do ano de Johnson, Descrição de batalha de Kluge e $O$ curto verão da anarquia de 
Enzensberger aponta para o fato de que na construção geral destes romances uma descrição de estruturas tomou o lugar da narrativa encadeada. O recorte temporal também ostensivamente exíguo do Ulysses de Joyce desponta como modelo distante. A historiografia anglo-saxônica já havia desenvolvido há tempos tais esquemas de corte transversal pelas estruturas como forma de investigação demográfica e quantificante; e na França, para além das contribuiçóes da revista Annales, a histoire structurelle não só abrira largo caminho (42) como também já havia estabelecido novas ligações com técnicas narrativas tradicionais. $E$, nisso, foi exatamente na França, entre os teóricos do neo-estruturalismo, que se propagara uma condenação categórica da exposição narrativa de acontecimentos pretéritos. Por Braudel e depois por Roland Barthes até Foucault, a história narrada foi apresentada não apenas como uma exposiçáo ficcional, mas também como a propriamente ideológica (43), e isto porque ela reveste afirmaçóes com a aparência de reprodução de fatos e, pelo menos em sua forma pura, não se lança à busca de fundamentos. Por isso, um narrador não poderia senão apresentar sua "ilusão subjetiva" do passado.

Não se vai querer de forma alguma aproximar o Noupeau roman, sem mais nem menos, de uma historiografia especializada. Mas o programa de RobbeGrillet de destituir suas figuras de todo heroísmo e seus repetidos ataques contra "a ordem estabelecida da fixação no visgo ideológico", de caráter narrativo, pertencem a esse contexto (44); e no final das contas, também a bela moça nua que no filme de Robbe Grillet Glissements progressifs du plaisir se contrapóe, como alegoria da liberdade, à "ordem dominante da forma narrativa" está bem mais do que o seu criador quer perceber dentro das convençóes contemporâneas. Pois ela aparece menos como pessoa em carne e osso do que como um princípio construído um tanto forçadamente, o qual há muito tempo não encontra mais, entre os policiais e juízes que Robbe-Grillet posta ao seu redor, alguém que lhe mova ainda hoje um processo.

Enquanto o método historiográfico vem sendo discutido na Alemanha, desde os anos 70, com muito empenho, e representaçóes estruturais de épocas históricas foram testadas pelo menos em algumas investidas - Hans-Ulrich Wehler tenta assim expor $O$ Império alemão 1871-1918 não como de costume à sombra dos monumentos de Bismarck e Guilherme II, mas segundo seus "elementos estruturais" de reforma agrária, revolução industrial e restituição do estado militar e burocrático (45) -, os romances contemporâneos deixaram há tempos de entregar a história a indivíduos isolados, e por isso eles testemunham os processos que descrevem não mais com o depoimento de um narrador, mas sim com uma ordenação paralela de perspectivas pessoais diversas e campos de observação. Sínteses, eles só as impõem, como Alexander Kluge, aos seus leitores (46), sabendo muito bem que os leitores por seu turno são apenas pessoas particulares com suas concepçóes subjetivamente limitadas. 
Muito ao contrário da historiografia, os romancistas tentam com isso assegurar nova autenticidade às suas composiçóes ficcionais da história recente. Divergindo de uma historiografia social que, por exemplo, trabalha sobretudo analiticamente, eles não podem renunciar a pessoas de carne e osso. Mas ao expor de forma radical a subjetividade da perspectiva pessoal, ganham uma nova verdade. Eles demonstram a refração necessária - e porventura múltipla e subjetiva - na conversão de notícias do passado e, ao mesmo tempo, facilitam o processo dessa conver'são ao fazer com que o passado se reproduza preponderantemente em cima de testemunbos lingüisticos legados. Assim, os romancistas não apenas se furtam ao sofrível debate sobre as relações que os fatos estabelecem com sua transformação em escrita - eles também tornam nítido que, na realidade, narrativas e tradições escritas determinam em grau elevado a visão de História do indivíduo e, em última instância, também visões coletivas de História.

Nos últimos anos, todavia - depois de uma série de decepçóes em relação às metas de início muito ambiciosas colocadas por uma historiografia estrutural ressurgiu nos dois âmbitos, na historiografia e na arte romanesca, um surpreendente prazer no narrar. Esse novo pendor pela narrativa tira seus atrativos da descoberta de que não são os acontecimentos externos que devem ser reproduzidos, mas sim processos de consciência e discursos que se fazem sobre isso no medium da linguagem. Em todo caso, um romance que na Feira do Livro de Frankfurt de 1988 desencadeou ovações ao mesmo tempo nos jornais Faz e Zeit, assim como na revista Der Spiegel: O último mundo de Christoph Ransmayr (47) desvenda com um recurso especial as ilusóes que ainda podem insinuar-se também nessas novas "histórias das mentalidades". Trata-se da história de vida do Ovídio exilado. Acompanhada de uma visão panorâmica da capital Roma e da esquecida Tomi junto ao Mar Negro, a história é contada em grande parte como o processo de elaboração interior de um amigo que procura o desaparecido Ovídio. Mas o autor se faz notar, em sua própria pessoa e de maneira inequívoca, ao projetar em sua história requisitos do século $\mathrm{XX}$ - fitas cinematográficas, microfones - e demonstra com eles a natureza das instituições com as quais se produziam na era romana mentalidades coletivas. Dessa forma o autor não apenas desenvolve poderosa sátira do presente, mas também mostra sem floreios quais são as concepções próprias que balizam sua animação do passado.

Para o romancista um tal entrelaçamento de passado e presente pode bem ser um jogo com mascaramentos permitidos. Trata-se antes, porém, de um desmascaramento - não apenas no que diz respeito à maneira de Foucault de derivar história de mentalidades a partir de instituições. Pois com o emprego da moderna terminologia para as instituiçóes romanas formadoras de opiniôes, o narrador diz abertamente aquilo que para os historiadores é particularmente difícil dizer, embora já Droysen, quando acrescentou outros modelos expositivos à narrativa embasante, tenha proposto para isso o topos "exposição discussiva"* 
(48): Ransmayr deixa o contemporâneo de Ovídio falar e fala ele próprio não apenas a partir do seu presente, mas também do seu presente - justamente com um "repertório ovidiano".

Se antigos testemunhos lingüísticos contribuem muito, talvez ao máximo, para embasar as visóes de História da posteridade, então uma espécie de texto tem a função exclusiva de fazer isto: o discurso fúnebre. Nicole Loraux, em seu livro com o subtítulo objetivo Histoire de l'oraison funèbre dans la cité classique, analisa luminosamente como, em uma longa cadeia de tais discursos, a imagem da cidade de Atenas e de seus cidadáos é - da perspectiva dos que vêm depois ocupada de maneira sempre nova e, nesse mesmo processo, consolidada topicamente; a autora deu a esse estudo o expressivo título Linvention d'Athènes. A "Athènes imaginaire" que assim se originou, Nicole Loraux a chama "constitution discoursive d'une polis exemplaire", a qual não pode ser ignorada por ninguém que, pensando ou escrevendo, volte a defrontar-se com essa cidade construída pelo discurso (49). Justamente o sem-número das diferentes memórias da cidade - surgidas a partir da era helenística - garantem o paradoxo de que a idéia de uma "Atenas eterna" permaneça continuamente viva.

Se frente a uma tal produção implícita de visões de História e também frente à historiografia categórica ainda resta alguma coisa para o romance, então é aquilo que a literatura ficcional, em todos os tempos, sempre teve de vantagem sobre a historiografia: romances podem, com a força imagética imediata de seus textos, não apenas animar o diálogo entre o passado e o presente de seus leitores de forma sempre nova, como podem também desentranhar uma visão de relaçóes de vida para as quais nem as instituiçóes sociais nem as ciências jamais encontraram, no passado ou no presente, soluçốes compatíveis com a dignidade humana.

Historiografia e romance oferecem, cada um a seu modo, versóes da realidade. Mas o romance, como Uwe Johnson escreveu da Villa Massimo em Roma poucos anos antes de sua morte, sempre contrapõe um mundo próprio "ao mundo" (50). Isto quer dizer: a História no romance é também sempre futuro.

* O termo "exposição discussiva" (neologismo criado pelo próprio Droysen) designa o procedjmento de discutir um determinado acontecimento ou processo histórico a partir de pontos de vista do presente. Trata-se, portanto, de uma abordagem atualizante do material histórico, a qual busca extrair do passado subsídios para a solução de questões atuais. (N. d. T.)

\section{Notas}

1 Friedrich von Blanckenburg. Versuch über den Roman (1774; impressão fac-similar Sturtgart: Metzler, 1965) p.379. 
2 Augustin Thierry, "Briefe über die Geschichte Frankreichs" (Prefácio), Geschichte und Geschichtsschreibung. Möglichkeiten - Auffaben - Methoden. Texte von Voltaire bis zur Gegenwart (Munique: Piper, 1966) p. 70. Primeiramente: "Préface", Lettres sur l'histoire de France, pour semir d'introduction à l'étude de cette histoire (segunda edição retrabalhada, Paris: Sautelet, 1829): "Je voulais mettre en évidence le caractère démocratique de l'établissement des communes, et j'ai pensé que j'y réussirais mieux en quittant la dissertation pour le récit, en m'effaçant moi-même et en laissant parler les faits"(p. 3).

3 Roland Barthes, "Heute: Michelet" (1973), Michelet (Frankfurt a.M.: Athenaum, 1980) p. 9. Barthes caracteriza aqui sua leitura de Michelet feita há duas décadas e publicada primeiramente como livro em 1954.

4 Thomas Babington Macaulay, "History" (versão resumida), Geschichte und Geschichtsschreibung (v. nota 2) p. 90. The Works of Lord Macaulay, 12 vol. (Londres, 1898) vol. 7: "If a man, such as we are supposing, should write the history of England, he would assuredly not omit the battles, the sieges, the negotiations, the seditions, the ministerial changes. But with these he would intersperse the details which are the charm of historical romances"(p. 216 e ss.) V. Paul Michael Lützeler, "Bürgerkriegs-Literatur. Der historische Roman im Europa der Restaurationszeit (1815-1830)", Bürgertum im 19. Jahrbundert, vol. 3 (Munique: dtv, 1988) p. 232-56.

5 Leopold von Ranke, "Vorrede" (1824), Geschichten der romanischen und germanischen Völker von 1494 bis 1514. In Sämtliche Werke, 54 vol. (Leipzig: Duncker und Humblot, 1876-90) vol. 33-34.

6 Johann Gustav Droysen, "Grundriss der Historik” (versão de 1892), Historik (Stuttgart/Bad Cannstatt: Frommann-Holzboog, 1977), vol. 1: p. 417.

7 Victor von Scheffel, "Vorwort", Ekkehard. Eine Geschichte aus dem 10. Jabrhundert. In Werke, 4 vol. (Leipzig: Bibliographisches Institut, 1919) vol. 3: p. 20-25.

8 Conrad Ferdinand Meyer, Jürg Jenatsch. Eine Bündnergeschichte. In Sümtliche Werke (Berna: Benteli, 1958-75) vol. 10. Sobre Bismarck como modelo v. Georg Lukács, Der bistorische Roman, in Werke, vol. 6, Probleme des Realismus 3 (Neuwied e Berlim: Luchterhand, 1965) p. 237 ess.

9 Numa Denis Fustel de Coulanges, Histoire des institutions politiques de l'ancienne France, 6 vol. (Paris: Hachette, 1875-92).

10 Foi Christian Meier quem primeiro levantou essas questôes para - em relação à diferenciação feita por Hermann Lübbe entre "explicação histórica e nomológica" - objetar que se poderia responder historicamente também à segunda questáo. V. Christian Meier, "Narrativität, Geschichte und die Sorge des Historikers", Geschichte - Ereignis und Erzäblung (Munique: Fink, 1973), p. 572.

11 Richard Hennig, Columbus und seine Tat. Eine kritische Studie über die Vorgeschichte der Fahrt von 1492 (Bremen: Geist, 1940). V. em especial a consideraçáo final "Das Gesamt-Charakterbild des Columbus"(p. 164-69).

12 Johan Huizinga, "Über eine Formverwandlung der Geschichte seit der Mitte des XIX. Jahrhunderts", Im Bann der Geschichte. Betrachtungen und Gestaltungen (Amsterdam: Pantheon, 1942) p. 107-28.

13 Huizinga, p.121.

14 Lawrence Stone, "Die Rückkehr der Erzählkunst. Gedanken zu einer neuen alten 
Geschichtsschreibung", Vom Umschreiben der Geschichte. Neue historische Perspektiven (Berlim: Wagenbach, 1986) p. 91.

15 Huizinga (v. nota 12 ) p. 125 e ss.

16 L'Épolution de l'Humanité, 100 vol. org. p. Henri Berr. 65 vol. (Paris: La Renaissance du livre, 1920-38; Michel, 1939,54).

17 Lord Acton, "Brief an die Mitarbeiter der Cambridge Modern History", Geschichte und Geschichtsschreibung (v. nota 2), p.255.

18 Helmut Böhme, Prolegomena zu einer Sozial - und Wirtschaftsgeschichte Deutschlands im 19. und 20. Jabrbundert. edition suhrkamp 253 (Frankfurt a.M.: Suhrkamp, 1968).

19 Leopold von Ranke, "Einleitung", Geschichte der romanischen und germanischen Volker pon 1494-1514 (v. nota 5) p. XV.

20 V. a esse respeito Hans Peter Jaeck, "Zum Ursprung des Marxschen Terminus 'Gesellschaftsformation' “, Probleme der geschichtmissenschaftlichen Erkenntnis (Colônia: Kiepenheuer \& Witsch, 1978), p. 211 e ss.

21 Friedrich Wilhelm Joseph von Schelling, Philosopbie der Kunst. In Sämtliche Werke, 14 vol. (Stuttgart e Augsburg: Cotta, 1856-61) vol. 5: p. 678.

22 Georg Lukács, "Erzählen oder Beschreiben? Zur Diskusion über Naturalismus und Formalismus", Essays über Realismus (Berlim: Aufbau, 1948) e: Wider den misserstandenen Realismus (Hamburgo: Claassen, 1958). - A esse respeito: Theodor W. Adorno, "Erpresste Versöhnung", Noten zur Literatur II (Frankfurt a.M.: Suhrkamp, 1961) pp. 152-87.

23 Christian Meier, "Von der Schwierigkeit, ein Leben zu erzählen. Zum Projekt einer CaesarBiographie", Theorie und Erzählung in der Geschichte, org. p. Jürgen Kocka e Thomas Nipperdey. Theorie der Geschichte, Beiträge zur Historik 3 (Munique: dtv, 1979) p. 229-58.

24 Josef Pekar, Wallenstein 1630-1634. Tragödie einer Verschwörung. 2 vol. (Berlim: Metzner, 1937).

25 Pekar, p. 147.

26 Johann Gustav Droysen, Historik (v. nota 6) p.224.

27 Golo Mann, Wallenstein. Sein Leben erzäblt von் Golo Mann (Frankfurt a.M.: Fischer, 1971).

28 Golo Mann, p. 646.

29 Golo Mann, p. 655.

30 Alfred Döblin, Wallenstein (1920; Olten: Walter, 1965).

31 Döblin, p. 552.

32 Axel Hecker, Geschichte als Fiktion. Alfred Döblins Wallenstein - eine exemplarische Kritik des Realismus. Epistemata: Reihe Literaturwissenschaft 31 (Würzburg: Königshausen und Neumann, 1968) p. 365.

33 Bernd Dauer, "Nouveau Roman, Nouveau Nouveau Roman: Literarische Avantgarde um 1960”, Französische Literatur in Einzeldarstellungen. Vol. 3 (Stuttgart: Metzler, 1982) p. 329. 
34 Uwe Johnson, Jahrestage. Aus dem Leben von Gesine Cresspabl. 4 vol. (Frankfurt a.M.: Suhrkamp, 1970-83) vol. 4: p. 1891.

35 Hayden White, Metahistory. The historical imagination in nineteenth-century Europe (Baltimore: Johns Hopkins UP, 1973). V. também: Tropics of Discourse. Essays in cultural criticism (Baltimore: John Hopkins UP, 1978); traduzido para o alemão sob o significativo título: Auch Klio dichtet oder Die Fiktion des Faktischen. Studien zur Topologie des historischen Diskurses. Introdução de Reinhard Koselleck. Sprache und Geschichte, org. p. R. Koselleck e Karlheinz Stierle, vol. 10 (Stuttgart: Metzler, 1986).

36 François Furet, "Die Methoden der Sozialwissenschaften in der Geschichtsforschung und die histoire totale", Theorie der modemen Geschichtsschreibung (Frankfurt a.M., 1987), p. 158.

37 Ferdinand Braudel, "Histoire et Science sociale. La longue durée", Annales 4 (1958): p. 725-53.

38 Roland Barthes, "Literatur oder Geschichte"(1960), Literatur oder Geschichte. edition suhrkamp 303 (Frankfurt a.M.: Suhrkamp, 1969) p. 22 e ss.

39 Alexander Kluge, Schlachtbeschreibung (Freiburg: Walter, 1964) e a versão modificada pela primeira vez: Fischer Bücherei 860 (Frankfurt a.M.: Fischer, 1968).

40 "Formenwelt, handelnde Personen" - assim intitulou Kluge, nas primeiras versões do seu livro Schlachtbeschreibung, o último capítulo. Nas edições posteriores, retrabalhadas a cada vez, alternam-se formulação e posição. Na edição com o título Der Untergang der Sechsten Armee (Schlachtbeschreibung) (Munique: Piper, 1969) "Formenwelt" aparece como último apêndice; o prefácio começa com a frase: "O livro descreve a construção organizadora de uma desgraça." Na versão revista e ampliada (Munique: Goldmann, 1978) e na edição subseqüente da edition suhrkamp (1193, Frankfurt a.M., 1983) o capítulo "Formenwelt", com o texto em parte ampliado e em parte resumido, está ordenado na metade do livro.

41 Hans Magnus Enzensberger, Der kurze Sommer der Anarchie. Buenaventura Durrutis Leben und Tod (Frankfurt a.M.: Suhrkamp, 1972). V. cm especial o capítulo: "Erste Glosse. Über dic Geschichte als kollektive Fiktion"(p. 12-16).

42 V. a esse respeito Krzysztof Pomian, "I'histoire des structures", La nouvelle histoire org. p. Jacques Le Goff, Roger Chartier e Jacques Revel (Paris: Retz, 1978) p. 528-53. Sobre isso também: François Furet, "Die Methoden der Sozialwissenschaften in der Geschichtsschreibung und die histoire totale" (v. nota 36) p. $158 \mathrm{c}$ ss.

43 A esse respeito Hayden White, "Das Problem der Erzählung in der modernen Geschichtstheorie", Theorie der modernen Geschichtsschreibung (v. nota 36) p. 65-68.

44 Cito aqui do levantamento de citaçốes feito por Bernd Dauer (v. nota 33), p. 296.

45 Hans-Ulrich Wehler, Das deutsche Kaiserreich 1871-1918 (Göttingen: Vandenhoek \& Ruprecht, 1973).

46 Assim nas declarações explanatórias sobre as edições posteriores (v. notas 39 e 40). Já na edição de 1968 Kluge escreve ao final de sua "Nachbemerkung": "O livro, como toda ficção, também aquela composta de material documental, contém um gradil no qual a fantasia do leitor pode agarrar-se quando se movimenta em direção de Stalingrado"(p. 237).

47 Christoph Ransmayr, Die letzte Welt. Roman. Mit einem Opidischen Repertoire (Nördlingen: Greno, 1988).

$48 \mathrm{~V}$. a esse respeito Werner Schiffer, Theorien der Geschichtsschreibung und ihre erzäbltheoretische 
Relevanz. Danto, Habermas, Baumgartner, Droysen (Stuttgart: Metzler, 1980), em especial o capítulo III: "Die Theorie der historischen Darstellungsformen in J. G. Droysens 'Historik" (p. 87-112); sobre a exposição discussiva: p. 100 e ss.

49 Nicole Loraux, Linpention d'Athènes. Histoire de l'oraison funèbre dans la "cité classique" (Paris: de Gruyter, 1981) p. 334.

50 Uwe Johnson, "Vorschläge zur Prüfung eines Romans" (1973), Romantheorie. Dokumentation ibrer Geschichte in Deutschland seit 1880. Org. p. Eberhard Lämmert, et al. AthenäumTaschenbücher 2180 ( $2^{3}$ edição Königstein, Taunus: Athenäum, 1984), p. 403.

\title{
Resumo
}

Há dois séculos a historiografia e o romance vêm se desenvolvendo, sob muitos aspectos, em tensa e estreita relação. Ambos são compelidos ao mesmo tempo a fundamentar o evento narrado de maneira mais detalhada do que anteriormente. As razóes para isso residem no fato de que a vantagem educacional do autor sobre o leitor está diminuindo. Além disso, como a responsabilidade pelo curso da história é atribuida antes a forças históricas coletivas ou pessoais do que a indivíduos, novas modalidades de representação tornam-se necessárias tanto para o historiador como para o romancista. Eles reagiram a essa crise emergente da narraçäo de diversas formas: por meios de especialização, através da pluralização de perspectivas, da descrição de estruturas mais do que pela narraçáo de eventos e, por fim, através de uma confissáo radical da subjetividade que rege o julgamento dos eventos retratados. A parcela que toda historiografia tem em comum com a ficção assim como o caráter voltado para o presente - ou para o futuro - da história representada no romance são assim legitimados.

\begin{abstract}
For two centuries historiography and the novel have been developing in competition with one another in many respects. At the same time, they are both compelled to confirm the narrated event in a more detailed manner than before. The reasons for this lie in the fact that the educational advantage of the author over the reader is diminishing. Furthermore, as soon as the responsibility for the course of history is no longer attributed to individuals but rather to collective or impersonal historic forces, new patterns of representation become necessary for the historiographer and the novelist alike. They have responded to this emerging crisis of narration in various ways: by means of specialization, through pluralization of perspective, through description of structure rather than narration of events, and finally, through a radical avowal of the subjective judgment of the depicted events. The portion that any historiography shares with fiction as well as the present and future - oriented character of history represented in the novel are thus legitimated.
\end{abstract}

Eberhard Lämmert é professor de teoria literária e literatura comparada da Universidade Livre de Berlim. $\hat{E}$ autor, entre outros, dos livros Formas estruturais da narrativa (1955), As ciências sociais na era industrial (1966) e O labirinto - destinos da literatura (1992). No dia 13 de abril de 1994, Lämmert fez no IEA-USP a palestra "Lidando com o sempre crescente volume do conhecimento humano".

Copyright revista The German Quarterly, v. 63, n. 1., p. 5-18.

Tradução de Marcus Vinicius Mazzari. O original em alemão - "Geschichte ist ein Entwurf": Die neue Glaubwïrdigkeit des Erzäblens in der Geschichtsschreibung und im Roman - encontra-se à disposição do leitor no IEA-USP para eventual consulta. 